\title{
The Current Situation of Internet Addiction and Its Impact on Sleep Quality and Self-Injury Behavior in Chinese Medical Students
}

\author{
Yanqiu Wang*, Ying Zhao*, Ling Liu, Yan Chen, Dong Ai, Yingshui Yao, and Yuelong Jin $\bowtie$ \\ Department of Epidemiology and Health Statistics, School of Public Health, Wannan Medical College, Anhui, China
}

Objective The purpose of this cross-sectional survey is to explore the current state of Internet addiction (IA) in Chinese medical students and its connection with medical students' sleep quality and self-injury behavior.

Methods Respondents were came from Wannan Medical College, China. The Young's Internet Addiction Test, Pittsburgh Sleep Quality Index (PSQI), Self-Harm Questionnaire were used in this cross-sectional survey. A total of 3,738 medical students were investigated, 1,552 (41.52\%) males, 2,186 (58.48\%) females. T-test, chi-square test and MANOVA were used for data analysis.

Results Of the 3,738 medical students, 1,054 (28.2\%) reported having IA, 1,126 (30.1\%) reported having poor sleep quality, 563 (15.1\%) having self-harm behaviors. IA tends to be more female, upper grade students. The sleep quality of IA was worse than that of non-IA $\left(\chi^{2}=54.882, p<0.001\right)$, and the possibility of self-injury was higher than non-IA $\left(\chi^{2}=107.990, p<0.001\right)$.

Conclusion This survey shows that the IA detection rate of medical students was $28.2 \%$. Females, higher grade students had a higher IA detection rate. The low sleep quality and self-injury behavior of medical students are associated with IA.

Psychiatry Investig 2020;17(3):237-242

Key Words Internet addition, Medical students, Sleep quality, Self-harm.

\section{INTRODUCTION}

Internet addiction (IA) is often defined as uncontrolled, excessive use of the internet. ${ }^{1}$ The clinical characteristics of Internet addiction usually include: online time is more than six hours a day, loss of control over the network, lose interest in other things, use the network to break free anxiety and depression. ${ }^{2,3}$ In 2015, the World Health Organization (WHO) reported that IA has become a global public health problem. ${ }^{4}$ College students become the main users of the Internet because of their easy access to the Internet and flexible time. ${ }^{5}$ According to ElSalhy et al. ${ }^{6}$ research, Japanese universities have

Received: May 24, 2019 Revised: September 29, 2019

Accepted: November 2, 2019

$\triangle$ Correspondence: Yuelong Jin, $\mathrm{PhD}$

Department of Epidemiology and Health Statistics, School of Public Health, Wannan Medical College, No 22 Road Wenchangxi, Yijiang District, Anhui 241002, China

Tel: +86-13965178350, E-mail: jinyl0803@163.com

*These authors contributed equally to this work.

(c) This is an Open Access article distributed under the terms of the Creative Commons Attribution Non-Commercial License (https://creativecommons.org/licenses/by$\mathrm{nc} / 4.0$ ) which permits unrestricted non-commercial use, distribution, and reproduction in any medium, provided the original work is properly cited.
$56.2 \%$ of problems due to excessive use of the Internet, and 3.8\% of those with more serious problems. In China, Li et al. research ${ }^{7}$ shows that the detection rate of adult IA was $10.5 \%$. However, the detection rate of IA in Chinese medical students (about $30.1 \%$ ) is much higher than that of non-medical students. ${ }^{8}$

Many surveys found that people with IA have very serious anxiety and depression. ${ }^{9}$ Regarding the relationship between anxiety and IA, Soulioti et al. ${ }^{10}$ study found that anxiety symptoms were moderately correlated with the overall score of IA. Tonioni et al..$^{11}$ found that the longer the Internet time, the less communication with people in the real world, the higher the anxiety and depression scores. And previous studies have shown that patients with IA have an increased probability of having attention deficit/hyperactivity disorder (ADHD). ${ }^{12}$

Studies have proved that poor sleep quality is associated with IA. A meta-analysis of 23 studies found that people who were addicted to the internet had significant symptoms of poor sleep quality and reduced sleep time..$^{13}$ Bruni et al..$^{14}$ survey on 840 teenagers and adults found that after 21:00, the longer the internet time, the more devices used, the greater the negative impact on sleep quality. Studies have reported that the higher the 
medical students use the network during sleeping times, the higher of IA score. ${ }^{15}$ Steinbüchel et al. ${ }^{16}$ conducted a systematic analysis of 10 studies and found that the prevalence for nonsuicidal self-injury and suicide rate in IA patients was higher than that in non-IA patients, and the prevalence range was 1.6-18.7\%. A cohort study found that Internet addicts without self-harm behavior were 2.41 times more likely to self-injury than non-Internet addicts after one year. ${ }^{17}$ In China, there was a research proof that in adolescents, the network experience related to self-harm. ${ }^{18}$

Considering the seriousness of IA and the increasing incidence, the research on medical students IA is less, and the relationship between medical students' Internet addiction status and sleep quality and self-injury behavior needs to be further studied. Therefore, students from Wannan Medical College, China were investigated to understand the detection rate of medical students IA and to explore the relationship between medical students' IA and sleep quality, self-injury behavior.

\section{METHODS}

\section{Participants and procedure}

This cross-sectional survey was conduction at the Wannan Medical College in Wuhu city Anhui province China, from September 2018 to November 2018. After stratifying according to the class of the college, 2,590 (69.3\%) freshmen, 624 (16.7\%) sophomores, and 524 (14.0\%) juniors were randomly selected. A total of 3,738 medical students were investigated, including 2,186 (58.48\%) females and 1,552 (41.52\%) males, the average age was $(18.80 \pm 1.18)$ years. Studies were anonymous in order to improve validity and authenticity of self-report. ${ }^{19}$ The investigators of this survey were composed of graduate student majoring in epidemiology and medical statistics at Wannan Medical College. Various professional counselors assisted in completing this survey. All participants signed an informed consent form. This study was approved by the Ethics Committee of Wannan Medical College (LL-2018BH08). A total of 3,800 questionnaires were sent out and 3,738 valid questionnaires were collected. The response rate was $98.37 \%$.

\section{Measures}

\section{Internet Addition Test}

Young et al. ${ }^{20}$ Internet Addiction Test (IAT) was used for this survey. This test consists of 20 questions, each with a total of 5 options ( $1=$ almost no, $2=$ occasionally, $3=$ sometimes, $4=$ often, $5=$ always). Scored the sum of 20 topic scores, $40-60$ for mild internet addiction, $60-80$ for moderate internet addiction, and 80-100 for severe internet addiction. ${ }^{21}$ The Cronbach alpha coefficient of this scale in this survey was 0.934 .

\section{Pittsburgh Sleep Quality Index}

Pittsburgh Sleep Quality Index (PSQI) was developed by Dr. Buysse et al., ${ }^{22}$ psychiatrist at the University of Pittsburgh. It consists of 19 self-evaluation items. The scale includes seven components: Subjective sleep quality, sleep latency, effective sleep time, sleep efficiency, sleep disorders, using hypnotic drugs, daytime dysfunction. The PSQI revised by Liu et al. ${ }^{23}$ was used in the survey. Each dimension is divided into four grades, namely $0,1,2,3$. The total PSQI score is the sum of seven dimensions, a total of 21 points. PSQI score greater than 7 points for poor sleep quality, the higher the score, the worse the sleep quality. ${ }^{24}$ The sensitivity and specificity of the scale for determining the normal and non-normal sleep quality were $98.3 \%$ and $90.3 \%$, respectively (Kappa $=0.89, \mathrm{p}<0.01$ ). The Cronbach coefficient between the components was 0.84 ; the Cronbach coefficient between the entries was 0.85 , and the coefficient of test-retest reliability was 0.81 . Therefore, the scale has high reliability and validity.

\section{Self-Harm Questionnaire}

The self-injury behavior questionnaire was compiled on the basis of the existing questionnaire. The respondent needs to fill in whether there have been five self-injury behaviors: ${ }^{25}$ 1) Causing psychological damage, such as deliberately degrading or insulting oneself. 2) Causes tissue damage, including intentional burns, bites, scratches, etc. 3) Potentially harmful self-injury, for example deliberate refusal to treat, intentional smoking, alcohol abuse, etc. 4) Highly lethal self-injury, intentional poisoning, deliberate investment in the river, etc. 5) No visible damage to the naked eye, such as deliberately licking your own hair, deliberately hitting your head, etc. Each self-injury behavior is divided into 0 times, $1-2$ times, $\geq 3$ times. $^{26}$ The total number of self-injury is equal to the highest number of five self-injury behaviors. The test-retest reliability after one week of the scale is 0.863 .

\section{Statistical analyses}

All statistical analysis was conducted by using SPSS 18.0 (SPSS Inc., Chicago, IL, USA). The Young' Internet Addiction Scale scores will examine the subject into two groups, the IA group with 40 points or more, and the non-IA group with less than 40 points. The t-test was used to compare the age between the two groups. Comparison of gender and grade between the two groups using chi-square test and Fisher's exact test. The relationship between the IA and the seven dimensions in the PSQI scale was analyzed by multivariate analysis of variance (MANOVA), and the relationship between IA and medical students' sleep quality was analyzed by $\mathrm{t}$-test. The relationship between medical students' IA and self-injury behavior was analyzed by using chi-square test. Statistical significance was set at $\mathrm{p}<0.05$. 


\section{RESULTS}

\section{Demographic characteristics}

In the 3,738 students, a total of 1,054 (28.2\%) have IA (IAT score higher than 40). Among them, 404 (26.0\%) male and 650 (29.7\%) of female with IA Demographic characteristics of two groups are seen in Table 1. Medical students with IA tend to be female $\left(\chi^{2}=6.150, \mathrm{p}=0.013\right)$, seniors $\left(\chi^{2}=14.955, \mathrm{p}=0.001\right.$, $\left.\mathrm{P}_{\text {trend }}=0.001\right)$.

\section{Relationship between IA and sleep quality}

As shown in Table 2, there were 1,126 people with low sleep quality, accounting for $30.1 \%$. IA people's sleep quality was lower than non-IA $\left(\chi^{2}=54.882, \mathrm{p}<0.001\right)$. Table 3 shows the relationship between IA and seven components of PSQI. IA tends to have poor subjective sleep quality, long sleep latency, short effective sleep time, low sleep efficiency, many sleep disorders, and more dysfunction during the day $(\mathrm{p}<0.001)$.

\section{Relationship between IA and self-injury behaviors}

As shown in Table 4, the total self-injury detection rate of IA (24.8\%) was higher than without IA $(11.3 \%)\left(\chi^{2}=107.990\right.$, $\mathrm{p}<0.001)$. Among the five self-injury behaviors of high lethality, tissue damage, no visible damage, potential harm, and psychological damage, the detection rates of IA were $1.4 \%, 5.7 \%$, $13.4 \%, 12.0 \%, 11.6 \%$, respectively and the non-IA were $0.7 \%$, $2.0 \%, 5.6 \%, 4.2 \%$, and $4.1 \%$, respectively. Medical students with IA had a significantly higher detection rate of five self-injury behaviors (all had $\mathrm{p}<0.001$ ).

\section{DISCUSSION}

In this survey, the IA detection rate of medical students in this university was $28.2 \%$.

This detection rate was higher than $\mathrm{Zhu}$ et al. ${ }^{27}$ findings on medical students in Shandong Province, China. However, another study found that Indian medical students' IA detection rate was $38.2 \%{ }^{28}$ The difference in IA detection rate of these

Table 1. Demographic characteristics of medical students with and without IA

\begin{tabular}{|c|c|c|c|c|c|}
\hline Item & No internet addiction $(\mathrm{N}=2,684)(\%)$ & Internet addiction $(\mathrm{N}=1,054)(\%)$ & $t / \chi^{2}$ & $\mathrm{p}$ & ptrend \\
\hline Gender & & & 6.15 & 0.013 & \\
\hline Male & $1,148(74)$ & $404(26)$ & & & \\
\hline Female & $1,536(70.3)$ & $650(29.7)$ & & & \\
\hline Age $($ mean $\pm S D)$ & $18.80 \pm 1.176$ & $18.79 \pm 1.199$ & 0.263 & 0.793 & \\
\hline Grade & & & 14.955 & 0.001 & 0.001 \\
\hline Freshman & $1,908(73.7)$ & $682\left(26.3^{\mathrm{a}}\right)$ & & & \\
\hline Sophomore & $427(68.4)$ & $197\left(31.6^{\mathrm{b}}\right)$ & & & \\
\hline Junior & $349(66.6)$ & $175\left(33.4^{\mathrm{b}}\right)$ & & & \\
\hline
\end{tabular}

Different letters represent differences between groups. a and b indicate different IA detection rates between the two groups, $\mathrm{p}<0.05$. IA: Internet addiction

Table 2. The impact of IA on sleep quality

\begin{tabular}{|c|c|c|c|c|c|c|}
\hline \multirow{2}{*}{ IA } & \multicolumn{2}{|c|}{ Poor sleep quality } & \multicolumn{2}{|c|}{ Normal sleep quality } & \multirow{2}{*}{$\chi^{2}$} & \multirow{2}{*}{$\mathrm{p}$} \\
\hline & \multicolumn{2}{|c|}{$\mathrm{N}(\%)$} & \multicolumn{2}{|c|}{$\mathrm{N}(\%)$} & & \\
\hline No & 715 & 26.6 & 1,968 & 1,968 & \multirow{3}{*}{54.882} & \multirow{3}{*}{$<0.001$} \\
\hline Yes & 411 & 39 & 643 & 643 & & \\
\hline Total & 1,126 & 30.1 & 2,612 & 2,612 & & \\
\hline
\end{tabular}

IA: Internet addiction

Table 3. The effect of IA on the seven components of PSQI

\begin{tabular}{cccccccc}
\hline IA & $\begin{array}{c}\text { Subjective } \\
\text { sleep quality }\end{array}$ & $\begin{array}{c}\text { Sleep } \\
\text { latency }\end{array}$ & $\begin{array}{c}\text { Effective } \\
\text { sleep time }\end{array}$ & $\begin{array}{c}\text { Sleep } \\
\text { efficiency }\end{array}$ & $\begin{array}{c}\text { Sleep } \\
\text { disorders }\end{array}$ & $\begin{array}{c}\text { Using hypnotic } \\
\text { drugs }\end{array}$ & $\begin{array}{c}\text { Daytime } \\
\text { dysfunction }\end{array}$ \\
\hline Yes $($ mean \pm SD) & $0.73 \pm 0.67$ & $0.63 \pm 0.74$ & $0.96 \pm 0.44$ & $0.64 \pm 0.27$ & $0.60 \pm 0.53$ & $0.02 \pm 0.24$ & $1.21 \pm 0.85$ \\
No $($ mean \pm SD) & $0.97 \pm 0.72$ & $0.87 \pm 0.84$ & $1.04 \pm .0 .46$ & $0.72 \pm 0.27$ & $0.81 \pm 0.57$ & $0.04 \pm 0.27$ & $1.73 \pm 0.91$ \\
F & 89.238 & 68.240 & 27.549 & 71.940 & 102.378 & 2.392 & 273.488 \\
p & $<0.001$ & $<0.001$ & $<0.001$ & $<0.001$ & $<0.001$ & 0.122 & $<0.001$ \\
\hline
\end{tabular}

IA: Internet addiction, PSQI: Pittsburgh Sleep Quality Index 
Table 4. The effect of IA on self-injury behavior of medical students [N (\%)]

\begin{tabular}{|c|c|c|c|c|c|c|c|c|c|c|c|c|}
\hline \multirow[t]{2}{*}{ IA } & \multicolumn{2}{|c|}{$\begin{array}{c}\text { Causing psychological } \\
\text { damage }\end{array}$} & \multicolumn{2}{|c|}{$\begin{array}{c}\text { Causes tissue } \\
\text { damage }\end{array}$} & \multicolumn{2}{|c|}{$\begin{array}{c}\text { Potentially harmful } \\
\text { self-injury }\end{array}$} & \multicolumn{2}{|c|}{$\begin{array}{l}\text { Highly lethal } \\
\text { self-injury }\end{array}$} & \multicolumn{2}{|c|}{$\begin{array}{l}\text { No visible damage } \\
\text { to the naked eye }\end{array}$} & \multicolumn{2}{|c|}{$\begin{array}{c}\text { Total } \\
\text { self-injury }\end{array}$} \\
\hline & No & Yes & No & Yes & No & Yes & No & Yes & No & Yes & No & Yes \\
\hline \multicolumn{13}{|l|}{ Yes } \\
\hline $\mathrm{N}$ & 2,573 & 111 & 2,630 & 54 & 2,571 & 113 & 2,666 & 18 & 2,533 & 151 & 2,382 & 302 \\
\hline$\%$ & 95.9 & 4.1 & 98 & 2 & 95.8 & 4.2 & 99.3 & 0.7 & 94.4 & 5.6 & 88.7 & 11.3 \\
\hline \multicolumn{13}{|l|}{ No } \\
\hline $\mathrm{N}$ & 932 & 122 & 994 & 60 & 928 & 126 & 1,039 & 15 & 913 & 141 & 793 & 261 \\
\hline$\%$ & 88.4 & 11.6 & 94.3 & 5.7 & 88 & 12 & 98.6 & 1.4 & 86.6 & 13.4 & 75.2 & 24.8 \\
\hline \multicolumn{13}{|l|}{ Total } \\
\hline $\mathrm{N}$ & 3,505 & 233 & 3,624 & 114 & 3,499 & 239 & 3,705 & 33 & 3,446 & 292 & 3,175 & 563 \\
\hline$\%$ & 93.8 & 6.2 & 97 & 3 & 93.6 & 6.4 & 99.1 & 0.9 & 92.2 & 7.8 & 84.9 & 15.1 \\
\hline$\chi^{2}$ & \multicolumn{2}{|c|}{71.662} & \multicolumn{2}{|c|}{34.676} & \multicolumn{2}{|c|}{63.147} & \multicolumn{2}{|c|}{75.838} & \multicolumn{2}{|c|}{75.838} & \multicolumn{2}{|c|}{107.99} \\
\hline $\mathrm{p}$ & \multicolumn{2}{|c|}{$<0.001$} & \multicolumn{2}{|c|}{$<0.001$} & \multicolumn{2}{|c|}{$<0.001$} & \multicolumn{2}{|c|}{$<0.001$} & \multicolumn{2}{|c|}{$<0.001$} & \multicolumn{2}{|c|}{$<0.001$} \\
\hline
\end{tabular}

IA: Internet addiction

studies may be due to 1) the sample sizes, 2) the educational environments, 3 ) the questionnaires of IA. In addition, our study found that female medical students have higher IA detection rates compared with male medical students $(\mathrm{p}=0.013)$. This may be because females were more shy than males, therefore they were more willing to make friends online and shopping rather than socializing, and studies have shown that shyness can predict IA. ${ }^{29}$ Our study also found that IA were higher among senior grade medical students than lower grade medical students, that may be because the senior medical students have adapted to the life of the university, so they have more time and energy to go online, which increases their risk of IA.

Many studies have found that IA is related to sleep quality. ${ }^{30,31}$ As expected, the relationship between medical students' IA and sleep disorders was confirmed in this study. The study found that IA was associated with mental illness such as depression and anxiety, which affect sleep quality. ${ }^{11}$ According to reports, a possible mechanism by which IA caused sleep disorders is that medical students with IA had long-term exposure and light source, leading to inhibition of melatonin secretion. ${ }^{32}$ And another mechanism is that the brain is over-excited due to prolonged use of the Internet, leading to a series of sleep problems, such as difficulty falling asleep, easy to wake up, and low sleep efficiency. Shen et al. ${ }^{33}$ research proved this mechanism that people who play mobile phones for 60 minutes before going to bed have a higher probability of having a sleep disorder than those who have played for 10 minutes before going to bed. Some other reasons may explain this phenomenon: Radiation from computers and mobile phones can have a negative impact on the user's nervous system, which can lead to headaches, mental discomfort, decreased sleep quality, and in- creased dysfunction during the day.

Moreover, this study found that the incidence of psychological damage, tissue damage, potential damage, high mortality and no obvious damage in the IA was higher than non-IA. The result is similar to Pan and Yeh ${ }^{17}$ study. Huang ${ }^{34}$ conducted a study on 27,599 adolescents in Chongqing, China, and reported that the scores of SCL-90 among Internet addicts were higher than those of non-network addicts, and the more serious Internet addiction, the greater the psychological problems, the more impulsive and aggressive the out. The relationship between medical students' IA and self-injury behavior may be because IA people have impulsive control obstacles, and their uncontrollable behaviors that hurt themselves. ${ }^{35}$ Dong et al. ${ }^{36}$ examined the brain potentials of 12 IA students and 12 non-IA students. They found that the IA's nogo-n2 amplitude was lower, the nogo-p3 amplitude was higher, and the nogo-p3 peak latency was longer compared with the normal group. It indicated that IA patients had low efficiency in processing information and had reduced tolerance to frustration and adverse emotions, so they would relieve stress through self-injury. 37,38

However, there are several limitations in this study. First, owing to the cross-sectional was used in this survey, there may be recall bias in the process of responding to the survey of Internet, sleep and self-injury in the past period. Second, due to cross-sectional studies, causality may not be verified. Third, because the medical students surveyed are from only one medical university, the representativeness of the sample may be poor. Fourth, because other mental problems may also affect sleep quality and self-injury behavior, this study only considered the impact of IA on sleep quality and self-injury behavior, and the results may have errors. Fifth, there was no corresponding intervention for IA patients in this survey, and no 
follow-up of medical students with self-injury in IA.

Overall, this survey found that the IA detection rate of medical students was $28.2 \%$, and the females (29.7\%) were higher than males (26.0\%), and IA tends to be higher grade students. Medical students' IA was associated with decreased sleep quality. Compared with non-IA, medical students with IA tends to have poor subjective sleep quality, long sleep latency, short effective sleep time, low sleep efficiency, many sleep disorders, and more dysfunction during the day. The detection rate of these five self-injury behaviors (high lethal self-injury behavior, self-injury behavior caused by tissue damage, self-injury behavior with potential harm, no self-injury behavior visible to the naked eye, causing psychological injury self-injury behavior) of medical students were higher than that of non-IA. Based on the findings of this study, some suggestions have been made: Firstly, the harm of IA and how to use the Internet healthily should be popularized by the school in the form of lectures. Then, the counseling room should be established to guide the medical students with IA. Thirdly, the medical college should organize extracurricular activities to increase the amount of medical students' exercise and reduce the time spent online. Finally, I hope that the results of this article will lead to more in-depth research on the attention of experts in IA, sleep quality and self-injury behavior, and provide more detailed strategies for the prevention and treatment of IA.

\section{Acknowledgments}

We are very grateful to the undergraduates, teachers and graduate students who participated in this survey.

1. Excellent Young Talents Supporting Program of Colleges and Universities in Anhui Province (2014 Anhui Provincial Department of Education).

2. Research on the Influence of College Students' Internet Addiction on Physical and Mental Health (SK2018A0204).

3. Research on Prevention and Cure Strategy of College Students' Psychological and Behavioral Health from the Perspective of Preventive Medicine (SK2016A0947).

4. Anhui famous teachers' studio (2014msgzs151).

5. 2016 Key Projects for Academic Support for Top-Level Talents in Universities (Professional) (gxbjZD2016073).

\section{Conflicts of Interest}

The authors have no potential conflicts of interest to disclose.

\section{Author Contributions}

Conceptualization: Yanqiu Wang, Ying Zhao. Data curation: Yanqiu Wang, Ying Zhao. Formal analysis: Yanqiu Wang, Ying Zhao. Funding acquisition: Dong Ai, Yingshui Yao, Yuelong Jin. Investigation: Yanqiu Wang, Ying Zhao, Ling Liu, Yan Chen. Methodology: Yanqiu Wang, Ying Zhao, Ling Liu, Yan Chen. Project administration: Dong Ai, Yingshui Yao, Yuelong Jin. Resources: Dong Ai, Yingshui Yao, Yuelong Jin. Software: Yanqiu Wang, Ying Zhao. Supervision: Yan Chen, Dong Ai, Yingshui Yao, Yuelong Jin. Validation: Yanqiu Wang, Ying Zhao. Visualization: Yanqiu Wang, Ying Zhao, Ling Liu, Yan Chen. Writing_original draft: Yanqiu Wang, Ying Zhao. Writing — review \& editing: Yanqiu Wang, Ying Zhao.

\section{ORCID iDs}

Yanqiu Wang https://orcid.org/0000-0002-8418-7305
Ying Zhao https://orcid.org/0000-0002-7287-2444

Ling Liu https://orcid.org/0000-0003-3196-1798

Yan Chen https://orcid.org/0000-0003-4242-1308

Dong Ai https://orcid.org/0000-0002-5867-1021

Yingshui Yao https://orcid.org/0000-0002-6690-4585

Yuelong Jin https://orcid.org/0000-0003-1505-4434

\section{REFERENCES}

1. Ko CH, Hsiao S, Liu GC, Yen JY, Yang MJ, Yen CF. The characteristics of decision making, potential to take risks, and personality of college students with Internet addiction. Psychiatry Res 2010;175:121-125.

2. Kuss DJ, Lopez-Fernandez O. Internet addiction and problematic internet use: a systematic review of clinical research. World J Psychiatry 2016;6:143-176.

3. Tao R1, Huang X, Wang J, Zhang H, Zhang Y, Li M. Proposed diagnostic criteria for internet addiction. Addiction 2010;105:556-564.

4. World Health Organization. Available at: https://afro.who.int/ sites/default/files/2017-06/9789240694811_eng.pdf2015. Accessed February 20, 2019.

5. Ni X, Yan H, Chen S, Liu Z. Factors influencing internet addiction in a sample of freshmen university students in China. Cyberpsychol Behav 2009;12:327-330.

6. ElSalhy M, Miyazaki T, Noda Y, Nakajima S, Nakayama H, Mihara S, et al. Relationships between Internet addiction and clinicodemographic and behavioral factors. Neuropsychiatr Dis Treat 2019;15:739-752.

7. Li G, Hou G, Yang D, Jian H, Wang W. Relationship between anxiety, depression, sex, obesity, and internet addiction in Chinese adolescents: A short-term longitudinal study. Addict Behav 2019;90:421-427.

8. Zhang MWB, Lim RBC, Lee C, Ho RCM. Prevalence of internet addiction in medical students: a meta-analysis. Acad Psychiatry 2018;42: 88-93.

9. Nath K, Naskar S, Victor R. A cross-sectional study on the prevalence, risk factors, and Ill effects of internet addiction among medical students in northeastern India. Primary Care Companion CNS Disord $2016 ; 18$.

10. Soulioti E, Stavropoulos V, Christidi S, Papastefanou Y, Roussos P. The relationship of internet addiction with anxiety and depressive symptomatology. Psychiatriki 2018;29:160-171.

11. Tonioni F, D’Alessandris L, Lai C, Martinelli D, Corvino S, Vasale M, et al. Internet addiction: hours spent online, behaviors and psychological symptoms. Gen Hosp Psychiatry 2012;34:80-87.

12. Evren B, Evren C, Dalbudak E, Topcu M, Kutlu N. Relationship of internet addiction severity with probable ADHD and difficulties in emotion regulation among young adults. Psychiatry Res 2018;269:494-500.

13. Alimoradi Z, Lin CY, Brostrom A, Bülow PH, Bajalan Z, Griffiths MD, et al. Internet addiction and sleep problems: A systematic review and meta-analysis. Sleep Med Rev 2019;47:51-61.

14. Bruni O, Sette S, Fontanesi L, Baiocco R, Laghi F, Baumgartner E. Technology use and sleep quality in preadolescence and adolescence. J Clin Sleep Med 2015;11:1433-1441.

15. Schmidt G, Valdez M, Farrell M, Bishop F, Klam WP, Doan AP. Behaviors associated with internet use in military medical students and residents. Mil Med 2019;184:750-757.

16. Steinbüchel TA, Herpertz S, Külpmann I, Kehyayan A, Dieris-Hirche J, Te Wildt BT. [Internet addiction, suicidality and non-suicidal selfharming behavior - a systematic review]. Psychother Psychosom Med Psychol 2018;68:451-461.

17. Pan PY, Yeh CB. Internet addiction among adolescents may predict self-harm/suicidal behavior: a prospective study. J Pediatr 2018;197: 262-267.

18. Liu HC, Liu SI, Tjung JJ, Sun FJ, Huang HC, Fang CK. Self-harm and its association with internet addiction and internet exposure to suicidal thought in adolescents. J Formos Med Assoc 2016;116:153-160.

19. Ramo DE, Howard L, Prochaska JJ. Reliability and validity of young 
adults' anonymous online reports of marijuana use and thoughts about use. Psychol Addict Behav 2012;26:801-811.

20. Young K, Pistner M, O’Mara J, Buchanan J. Cyber disorders: the mental health concern for the new millennium. CyberPsychol Behav 1999; 2:475-479.

21. Xin M, Xing J, Pengfei W, Houru L, Mengcheng W, Hong Z. Online activities, prevalence of Internet addiction and risk factors related to family and school among adolescents in China. Addict Behav Rep 2018;7:14-18.

22. Buysse DJ, Reynolds CF, Monk TH, Berman SR, Kupfer DJ. The Pittsburgh sleep quality index: A new instrument for psychiatric practice and research. Psychiatry Res 1989;28:193-213.

23. Liu XC, Tang MQ, Hu L, Wang AZ, Wu HX, Zhao GF, et al. Reliability and validity of the Pittsburgh Sleep Quality Index. Chin J Psychiatry 1996;29:103-107.

24. Niu J, Han H, Wang Y, Wang L, Gao X, Liao S. Sleep quality and cognitive decline in a community of older adults in Daqing City, China. Sleep Med 2016;17:69-74.

25. Su PY, Hao JH, Huang ZH, Tao FB. An investigation on self-harm episodes and their relationship with suicidal psychology and behaviors in 2713 college students. Chin J Epidemiol 2010;33:1267-1271.

26. Wang J, Wang YQ, Zhang Y, Yan C, Jin YL, Ying SY. Study on the status and influence factors of self injurious behavior of college students. Chin Journal of Disease Control \& Prevention. 2019;23:304-307. 6 authors + et al/ Journal in abbreviation.

27. Zhu YH, Guo JZ, Li M, Hu SJ, Luo S, Dong Y. Research on the present situation and influencing factors of internet addiction of medical students in Shandong province. Chin J Soc Med 2017;34:240-244.

28. Nitin A, Cherian AV, Christofer T, Bhat A, Thomas C, Prathyusha PV, et al. Internet use behaviors, internet addiction and psychological distress among medical college students: a multi centre study from South India. Asian J Psychiatry 2018;37:71-77.
29. Tang SY, Gao FQ. The regulating effect of social support in dealing with shyness and internet addiction. J Lianyungang Norm College 2016;113:71-73.

30. Do KY, Lee KS. Relationship between problematic internet use, sleep problems, and oral health in Korean adolescents: a national survey. Int J Environ Res Public Health 2018;15. pii: E1870.

31. Lam LT. Internet gaming addiction, problematic use of the internet, and sleep problems: a systematic review. Curr Psychiatry Rep 2014;16: 444.

32. Higuchi S, Motohashi Y, Liu Y, Maeda A. Effects of playing a computer game using a bright display on presleep physiological variables, sleep latency, slow wave sleep and REM sleep. J Sleep Res 2010;14:267-273.

33. Shen C, Dai J, Zhou Y, Sheng Q, Wang Z, Cai SJ, et al. Influence of cell phone overuse on sleep quality among university students in Jiangsu. Chin J Sch Health 2015;5:74-76, 80.

34. Huang Y. Suicidal Behavior Characteristics and Suicide Risk Assessment of Adolescent Internet Addicts. Chongqing: Medical University; 2018.

35. Dell'Osso B, Altamura AC, Allen A, Marazziti D, Hollander E. Epidemiologic and clinical updates on impulse control disorders: a critical review. Eur Arch Psychiatry Clin Neurosci 2006;256:464-475.

36. Dong G, Zhou H, Zhao X. Impulse inhibition in people with Internet addiction disorder: electrophysiological evidence from a Go/NoGo study. Neurosci Lett 2010;485:138-142.

37. Swannell S, Martin G, Scott J, Gibbsons M, Gifford S. Motivations for self-injury in an adolescent inpatient population: development of a selfreport measure. Australas Psychiatry 2008;16:98-103.

38. Kaess M, Durkee T, Brunner R, Vladmir C, Parzer P, Wasserman C, et al. Pathological internet use among European adolescents: psychopathology and self-destructive behaviours. Eur Child Adolesc Psychiatry 2014;23:1093-1102. 